\title{
Inteligentne węzły pomiarowe w bezprzewodowej technice pomiarowej
}

\begin{abstract}
Rozwój technologii teleinformatycznych $w$ zakresie budowy inteligentnych uktadów pomiarowych, komunikujacych się bezprzewodowo tworzy bazę do oceny dziatania funkcjonalnych układów pojazdu w trybie on-line. $W$ artykule omówiono sieci bezprzewodowe złożone z bardzo wielu inteligentnych węztów pomiarowych. Przedstawiono problematykę systemów MEMS, możliwości węzłów pomiarowych typu Mote, system operacyjny TinyOS oraz standard protokotu komunikacyjnego ZigBee.
\end{abstract}

\section{Wprowadzenie}

Miniaturyzacja urządzeń elektronicznych oraz znaczne zmniejszenie poboru mocy tych urządzeń, a także znaczny postęp w dziedzinie sprzętu teleinformatycznego i protokołów komunikacji bezprzewodowej, umożliwiły stworzenie bezprzewodowych sieci pomiarowych. Sieci te zawierają znaczą liczbę, komunikujących się ze sobą węzłów pomiarowych.

Analiza bezprzewodowej sieci pomiarowej jest dokonywana zarówno pod kątem architektury sprzętowej (hardware), jak i zastosowanych rozwiązań programowych (software).

Węzeł pomiarowy, którego istotą jest połączenie sensora, układu przetwarzającego sygnały oraz układu komunikacji nazwano inteligentnym węzłem pomiarowym [1, 2 i 5]. Posiada on zdolność do wykonywania zadań pomiarowych, wykonywania obliczeń numerycznych oraz komunikacji $\mathrm{z}$ otoczeniem. Poza częścią sprzętową, inteligentny węzeł pomiarowy zawiera oprogramowanie służące między innymi do filtracji sygnału, do samokalibracji, do kontroli wartości granicznych mierzonych wartości oraz do analizy statystycznej.

Podstawowe bloki inteligentnego węzła pomiarowego stanowią:

- układ pomiarowy (sensor) w technologii MEMS, przedstawiony w punkcie 2,

- elementy typu hardware: układ kondycjonowania sygnału, przetworniki analogowocyfrowe i cyfrowo-analogowe, mikrokontroler $\mathrm{z}$ wbudowanymi zasobami pamięci typu flash oraz układy synchronizacji wejścia i wyjścia, opisane w punkcie 3,

- oprogramowanie (software) zarządzające procesami przetwarzania danych i komunikacji (z układem rejestracji danych, $\mathrm{z}$ interfejsem użytkownika oraz z układami zewnętrznymi), przedstawione $\mathrm{w}$ rozdziale 4 ,

- standard protokołu komunikacyjnego ZigBee, opisany w rozdziale 5 .

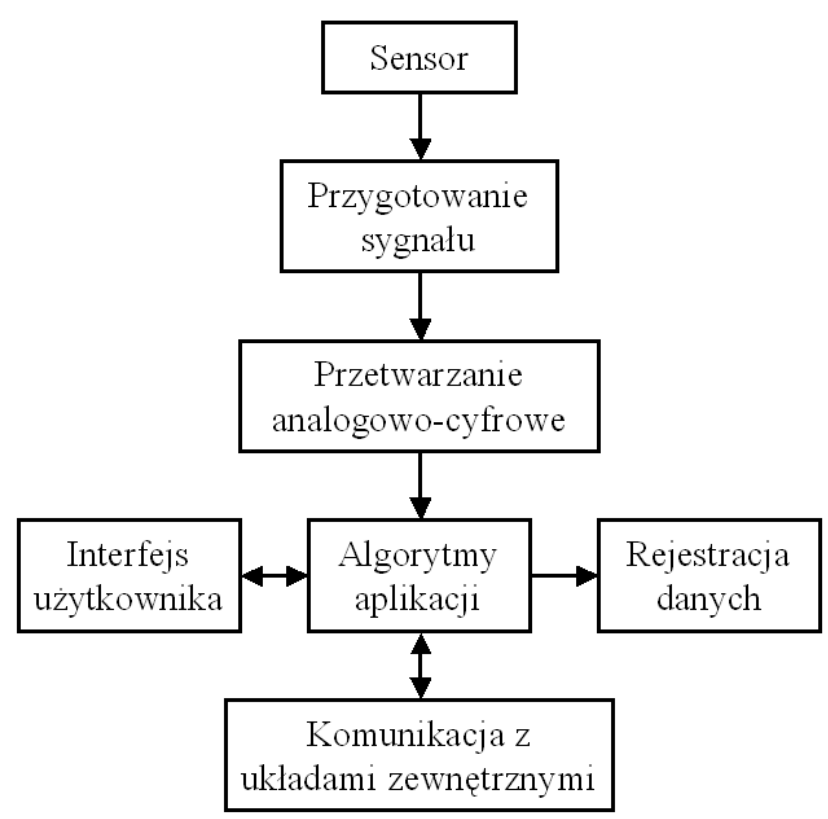

Rys. 1. Schemat ideowy inteligentnego węzła pomiarowego

\section{Technologia MEMS}

(MEMS - Micro-Electronic-Mechanical Systems) Czujniki mikro-elektroniczno-mechaniczne zrewolucjonizowały rynek czujników poprzez pojawienie się na nim tanich urządzeń o szybkiej odpowiedzi. Czujniki MEMS dziedziczą wiele cech układów scalonych, jednak różnią się od nich w sposób zasadniczy tym, że zawierają elementy mechaniczne takie jak: membrany, belki wspornikowe, sprężyny i inne [6]. Zastosowanie tych elementów umożliwia budowę różnorodnych czujników MEMS o bardziej efektywnych współczynnikach niż czujniki tradycyjne. Niewielkie gabaryty czujników MEMS są niezwykle istotną ich cechą umożliwiającą bezinwazyjne działanie w środowisku pomiarowym.

Układy, które tworzą czujniki MEMS są wytwarzane dzięki możliwościom technologii mikroobróbki krzemu oraz innych materiałów, zachodzącej począwszy 
od skali rzędu milimetrów do skali mikrometrów przy wykorzystaniu procesów stosowanych w przemyśle elektronicznym. Dzięki zastosowaniu tych technologii możliwe jest zbudowanie, rozrost, cięcie oraz łączenie bardzo małych elementów, które mogą zostać zintegrowane w taki sposób, że utworzą one urządzenie wykonujące określone zadania.

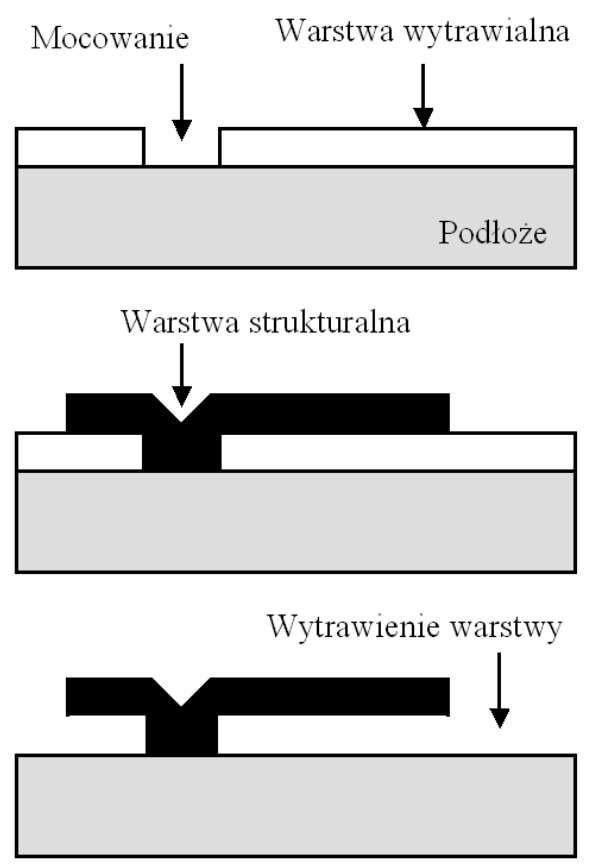

Rys. 2. Schemat ilustrujący ideę obróbki powierzchniowej układów MEMS

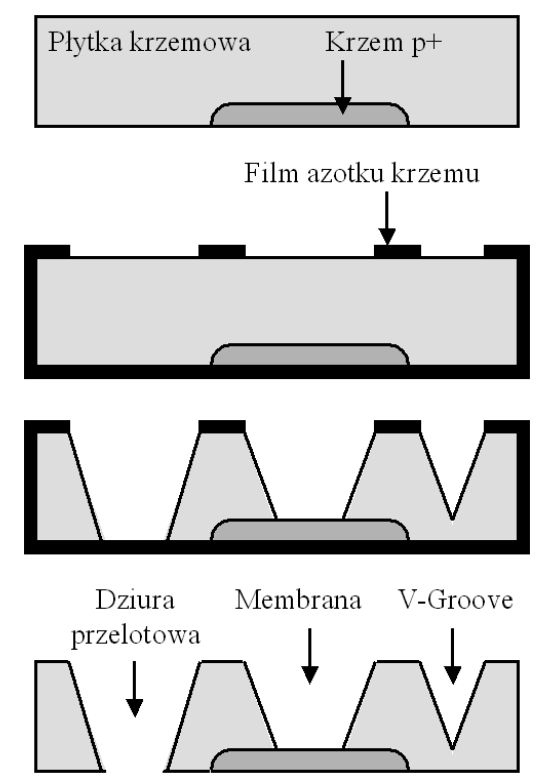

Rys. 3. Schemat ilustrujący ideę obróbki objętościowej układów MEMS

Czujniki są wytwarzane poprzez jednoczesne wykonywanie wielu operacji jednostkowych na silikonowym waflu. Po zakończeniu procesu produkcyjnego wafel zostaje pocięty na poszczególne jednostki sekcyjne zwane kośćmi, z których każda zawiera indywidualne urządzenie (przetwornik). Zakres średnic tych wafli wynosi od 50 do 450 milimetrów. Wymagane procesy produkcyjne mogą być często bardzo kosztowane, jednak koszty te rozkładają się na ogromna ilość kości zawartych na jednym waflu. W rezultacie - koszt jednostkowy poszczególnych przetworników jest bardzo niski, zważywszy masową produkcję.

Do produkcji przetworników stosuje się głównie technologie:

- fotolitografię

- mikroobróbkę powierzchniową (schemat ideowy przedstawiono na rys. 2)

- mikroobróbkę objętościową (schemat ideowy przedstawiono na rys. 3)

- spajanie.

Fotolitografia jest to proces, w którym wzór jest przenoszony na wafel poprzez wykorzystanie światła $\mathrm{i}$ materiałów światłoczułych. Technologia ta wymaga źródła światła, maski (czyli obiektu składającego się z sekcji przeźroczystych i nieprzeźroczystych) oraz materiału światłoczułego. W zaawansowanym procesie produkcyjnym, światło o określonej długości fali jest przepuszczane poprzez maskę na wafel pokryty światłoczułym polimerem, zwanym fotomaską. Jeśli fotomaska zostanie poddana ekspozycji światła, wówczas $w$ miejscach naświetlonych będzie ona cieńsza niż $\mathrm{w}$ miejscach nie poddanych ekspozycji. W ten sposób może ona zostać całkowicie usunięta $\mathrm{z}$ powierzchni wafla.

Mikroobróbka powierzchni polega na zbieraniu lub dodawaniu cienkich warstw materiału drogą wytrawiania lub osadzania. Mikroobróbka objętościowa polega na usuwaniu znacznie obszerniejszej oraz głębszej warstwy materiału. Realizuje się ją poprzez ekspozycję materiału na reaktywną ciecz, gaz lub plazmę. Proces ten można prowadzić izotropowo lub dokonywać jego modyfikacji w określonym kierunku (to znaczy - anizotropowo). Wytrawianie anizotropowe jest procesem najczęściej stosowanym, w którym w sposób selektywny usuwa się atomy silikonu $\mathrm{z}$ sieci krystalicznej w zależności od ich orientacji. Rezultatem tej obróbki jest powierzchnia, której gładkość jest na poziomie atomowym. Równie często stosowane jest wytrawianie za pomoca plazmy, w trakcie czego następuje anizotropowe cięcie promieniem światła. Warstwy wykonane $\mathrm{z}$ różnych materiałów (metali, azotków, tlenków oraz polimerów) mogą być osadzane na waflu. Możliwe jest również wprowadzanie domieszki do silikonu poprzez zastosowanie różnych technologii implantacji oraz dyfuzji w celu selektywnej, lokalnej zmiany mechanicznych lub elektrycznych własności silikonu.

Innym materiałem powszechnie stosowanym jest powstały w sposób naturalny dwutlenek krzemu, który charakteryzuje się innymi niż silikon własnościami mechanicznymi, elektrycznymi, chemicznymi oraz cieplnymi. 
Spajanie jest również ważnym procesem stosowanym w produkcji czujników MEMS. Bez możliwości spajania praktycznie nie byłaby możliwa produkcja skomplikowanych, trójwymiarowych układów. Technologia spajania pozwala również na wytwarzanie niezależnych części układów na różnych kościach oraz ich łączenie w celu uzyskania układów bardziej złożonych.

Połączenie tych procesów (oraz innych, bardziej specyficznych technologii, np. LIGA, DRIE) umożliwia produkcję wielu różnorodnych, mikroskopowych układów niezbędnych do budowy czujników MEMS o pożądanych funkcjach.

\section{Hardware}

Elementy bezprzewodowych sieci pomiarowych charakteryzują się niewielkimi rozmiarami i zdolnością do pomiaru i przetwarzania parametrów otoczenia za pomocą bardzo dokładnych zestawów czujników. Stosowane obecnie w czujnikach bezprzewodowych mikrokontrolery bazuja na tanich procesorach typu RISC (Redused Instruction Set Computer) i posiadaja niewielkie ilości pamięci, rzędu setek kilobajtów. Gdy wymaga tego aplikacja, do systemu dodana może zostać zewnętrzna pamięć typu flash, która charakteryzuje się jednak długim czasem dostępu oraz skończoną ilością zapisów (około 100 tysięcy razy), jednakże udostępnia o wiele większą przestrzeń adresowă, rzędu kilku megabajtów. Mikrokontrolery zawierają również uniwersalne, asynchroniczne układy nadawczo-odbiorcze UART (Universal Asynchronous Receiver-Transmitter), pozwalające na komunikowanie się z otoczeniem.
Pierwszą platformą sprzętowo-programową typu open (otwarty standard) dla inteligentnych węzłów pomiarowych jest platforma Berkeley Mote [4], która składa $\mathrm{z}$ czterech podstawowych komponentów:

- moduł zasilania

- moduł sensorów

- moduł przetwarzania danych

- modul komunikacyjny.

Konstruowanie inteligentnego węzła pomiarowego polega na wykorzystaniu platformy, która umożliwia dodawanie wymaganych układów. Dodawane autonomiczne moduły komunikują się poprzez szynę rozszerzeń (expansion bus).

Aktualnie na rynku dostępne są moduły trzeciej generacji platformy Berkeley Mote, nazwane odpowiednio Mica2, Mica2dot, MicaZ (rys. 4) [8] oraz BTnode 3 [7]. Porównanie podstawowych charakterystyk sprzętowych powyższych Mote'ów przedstawiono w Tabeli 1.

Jeśli wymiary i zgodność parametrów toru radiowego ze światowymi normami ma duże znaczenie dla realizowanego projektu, to optymalnym wyborem urządzenia jest CC2420 [4]. Za jego pomocą można zbudować stabilny, dwukierunkowy tor radiowy pracujacy w ogólnodostępnym paśmie $2,4 \mathrm{GHz}$.

Cechą charakterystyczną przedstawionego rozwiązania jest możliwość połączenia Mote'ów do płyt, na których umieszczone są sensory różnych typów. Zestawienie dostępnych sensorów dostępnych w ramach układów Mica2 przedstawiono w Tabeli 2 [8].

Przykładowo, płyta MTS310CA wyposażona jest w czujnik przyspieszeń ADXL202E, którego charakterystykę podano w Tabeli 3 .
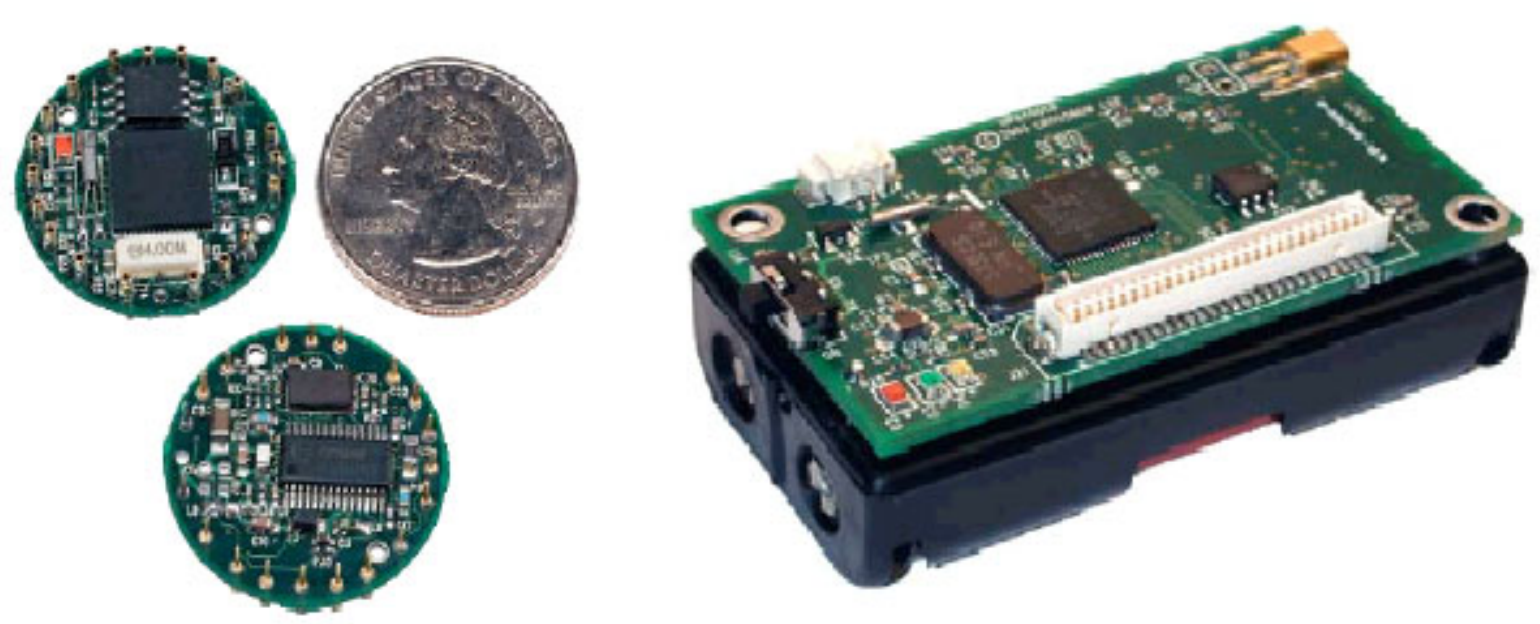

Rys. 4. Widok Mote’ów Mica2dot wielkości pensówki oraz Mika2/MicaZ 
Zestawienie parametrów wybranych urządzeń typu Mote.

Tabela 1

\begin{tabular}{|c|c|c|c|c|}
\cline { 2 - 5 } \multicolumn{1}{c|}{} & Btnode 3 & Mica2 & Mica2dot & MicaZ \\
\hline Producent & Art of Technology & CrossBow & CrossBow & CrossBow \\
\hline Mikrokontroler & Atmel Atmega & Atmel Atmega & Atmel Atmega \\
& $128 \mathrm{~L}$ & $128 \mathrm{~L}$ & $\begin{array}{c}\text { Atmel Atmega } \\
128 \mathrm{~L}\end{array}$ \\
\hline Zegar & $7,37 \mathrm{MHz}$ & $7,37 \mathrm{MHz}$ & $4 \mathrm{MHz}$ & $7,37 \mathrm{MHz}$ \\
\hline Pamięć RAM & $64+180 \mathrm{kB}$ & $4 \mathrm{kB}$ & $4 \mathrm{kB}$ & $4 \mathrm{kB}$ \\
\hline Pamięć ROM & $128 \mathrm{kB}$ & $128 \mathrm{kB}$ & $128 \mathrm{kB}$ & $128 \mathrm{kB}$ \\
\hline Pamięć flash & $4 \mathrm{kB}$ & $512 \mathrm{kB}$ & $512 \mathrm{kB}$ & $512 \mathrm{kB}$ \\
\hline Komunikacja & Chipcon CC1000 & Chipcon CC1000 & Chipcon CC1000 & Chipcon CC2420 \\
radiowa & $315 / 433 /$ & $315 / 433 /$ & $315 / 433 /$ & $2,4 \mathrm{GHz}$ \\
& $868 / 916 \mathrm{MHz}$ & $868 / 916 \mathrm{MHz}$ & $868 / 916 \mathrm{MHz}$ & $250 \mathrm{~kb} / \mathrm{s}$ \\
& $38,4 \mathrm{~kb} / \mathrm{s}$ & $38,4 \mathrm{~kb} / \mathrm{s}$ & $38,4 \mathrm{~kb} / \mathrm{s}$ & IEEE 802.15 .4 \\
\hline Maksymalny & $150-300 \mathrm{~m}$ & $150-300 \mathrm{~m}$ & $150-300 \mathrm{~m}$ & $750-100 \mathrm{~m}$ \\
zasięg & & & & $2 \mathrm{x}$ bateria AA \\
\hline Zasilanie & $2 \mathrm{x}$ bateria AA & $2 \mathrm{x}$ bateria AA & - & TinyOS \\
\hline System operacyjny & Nut/OS & TinyOS & TinyOS & - \\
\hline Bluetooth & TAK & - & - & \\
\hline
\end{tabular}

Zestawienie płyt z sensorami dla Mote'ów Mica2.

Tabela 2

\begin{tabular}{|c|c|c|c|c|c|}
\hline & MTS101CA & MTS300CA & MTS310CA & MTS400 & MTS400CA \\
\hline Fotorezystor & + & + & + & + & + \\
\hline Termistor & + & + & + & + & + \\
\hline Sensor akustyczny & & + & + & & \\
\hline Actuator akustyczny & & + & + & & \\
\hline Przyspieszeniomierz & & & & + & + \\
\hline $\begin{array}{c}\text { Przyspieszeniomierz } \\
\text { dwukierunkowy }\end{array}$ & & & + & & \\
\hline $\begin{array}{c}\text { Miernik pola } \\
\text { magnetycznego }\end{array}$ & & & + & & \\
\hline Higrometr & & & & + & + \\
\hline Barometr & & & & + & + \\
\hline GPS & & & & & + \\
\hline
\end{tabular}

Charakterystyka czujnika przyspieszeń ADXL202E znajdującego się na płycie MTS310CA. Tabela 3

\begin{tabular}{|r|c|c|c|c|}
\cline { 2 - 5 } \multicolumn{1}{c|}{} & Minimum & Typowo & Maksimum & Jednostka \\
\hline Zakres wartości wejściowy & & \pm 2 & $\mathrm{~g}$ & $\mathrm{~m} / \mathrm{s}^{2}$ \\
\hline Charakterystyka częstotliwościowa & & $0-6 \mathrm{kHz}$ & & $\mathrm{Hz}$ \\
\hline Napięcie pracy & 3 & & 5,25 & $\mathrm{~V}$ \\
\hline Prąd pracy & & 0,6 & 1 & $\mathrm{~mA}$ \\
\hline Czułośćc & 140 & 167 & 195 & $\mathrm{mV} / \mathrm{g}$ \\
\hline Szum wyjścia RMS & & 200 & & $\mu \mathrm{g} / \sqrt{\mathrm{Hz}}$ \\
\hline
\end{tabular}

\section{TinyOS}

Oprogramowanie działające $\mathrm{w}$ ramach inteligentnych węzłów pomiarowych wykonywane jest pod kontrolą systemu operacyjnego o nazwie TinyOS [10]. Jest to system operacyjny przechowywany w pamięci kontrolera Mote'a. Zapewnia on reakcje na zdarzenia i współbieżne wykonywanie wielu operacji realizowanych w sieci węzłów pomiarowych. Mote może korzystać między innymi z:
- oprogramowania planującego

- bazy danych

- programu obsługi łączności bezprzewodowej

- programu obsługi sieci przewodowej,

- oprogramowania zarządzającego zużyciem energii

- oprogramowania technologii kodowania zapewniającej poufność transmisji danych. 
System operacyjny TinyOS może kontrolować pracę Mote'ów typu Mica2, Mica2dot oraz MicaZ i jest z konieczności prostym rozwiązaniem, co wynika $z$ faktu, że węzeł czujnika jest urządzeniem o niewielkich zasobach pamięci.

TinyOS jest systemem operacyjnym typu open sour$c e, \mathrm{w}$ którym biblioteki, aplikacje oraz samo jądro systemu zostały zaimplementowane w języku strukturalnym nesC. Język nesC [3] powstał na potrzeby stworzenia oprogramowania dla dedykowanych systemów autonomicznych (embedded). Aplikacje napisane $\mathrm{w}$ języku nesC tworzone są z komponentów, czyli modułów programowych wymieniających dane poprzez tzw. interfejsy programowania. Dzięki temu programiści mogą tworzyć aplikacje z dostępnych na rynku komponentów, bez konieczności posiadania wiedzy na temat ich struktury wewnętrznej.

Baza systemu operacyjnego TinyOS jest trzypoziomowa architektura abstrakcji sprzętowej HAA (Hardware Abstraction Architecture). Najniższa warstwa HPL (Hardware Presentation Layer) tej architektury stanowi zespół podstawowych procedur wejścia/wyjścia, wartości rejestrów oraz sprzętowych ustawień zainstalowanego sprzętu. Drugim poziomem jest warstwa HAL (Hardware Abstraction Layer) udostępniająca pełną funkcjonalność wszystkich elementów sprzętowych systemu w sposób bardzo łatwy do wykorzystania przez programistów. Trzecia, najwyższa warstwa HIL (Hardware Independent Layer) udostępnia funkcje niezależne sprzętowo, co umożliwia programistom pisanie aplikacji wykorzystujących dowolny sprzęt kompatybilny z systemem operacyjnym TinyOS.

Model obsługi kilku procesów stosowany w nesC oparty jest na zdarzeniach. W ramach TinyOS istnieje tylko jedna kolejka zadań oczekujących na wykonanie, a jedno zdarzenie może zostać zgłoszone do obsługi tylko jeden raz, dlatego w przypadku zadań, które muszą być wykonywane cyklicznie w zadanym okresie czasowym, muszą one same ponownie siebie zgłaszać do wykonania.

Do pełnego wykorzystania możliwości systemu operacyjnego TinyOS niezbędne jest posiadanie odpowiednich narzędzi programowych. Narzędzia tego typu pozwalają na szybkie usuwanie błędów programowych w tworzonych aplikacjach, a także na detekcję uszkodzonego sprzętu. Przykładowo, komunikacja $\mathrm{w}$ ramach TinyOS realizowana jest poprzez następujace funkcje po stronie węzła nadawczego:

- ustalenie zawartości wysyłanego komunikatu

- ustalenie węzłów, do których komunikat jest adresowany
- ustalenie momentu zwolnienia pamięci zawierającą treść komunikatu

oraz funkcje realizowane po stronie węzła odbierającego:

- buforowanie odbieranego komunikatu

- przetwarzanie odebranego komunikatu.

Łączność bezprzewodową można realizować za pomoca protokołów ZigBee, IEEE 802.15.4 oraz Bluetooth (BTnode 3, Nut/OS) $[9,11]$.

\section{ZigBee}

Standard ZigBee wykorzystuje technologię radiową zdefiniowaną w ramach IEEE 802.15.4 uzupełniając ją o sieć logiczną oraz oprogramowanie związane $\mathrm{z}$ bezpieczestwem i aplikacjami użytkownika. Zgodność ze standardem IEEE zapewnia dużą kompatybilność we współpracy między urządzeniami pracującymi $\mathrm{w}$ tej technologii. ZigBee aspiruje do pozycji globalnego standardu obsługującego sieci inteligentnych węzłów pomiarowych.

Cechą znamienną technologii ZigBee jest bardzo mały pobór mocy wykorzystywanych urządzeń, pozwalający na zastosowanie baterii, które mogą służyć nawet kilka lat.

Architektura systemów ZigBee składa się warstw, z których każda zapewnia określony zestaw usług zgodnie ze strukturą komunikacji sieciowej OSI (Open Systems Interconnection). Architekturę systemów ZigBee przedstawiono na rys. 5.

Standard IEEE 820.15.4 definiuje dwie najniższe warstwy: fizyczną PHY (phisical) oraz podwarstwę łącza danych MAC (Media Access Control). ZigBee zdefiniowało warstwę sieciową NWK (network) i strukturę dla całej warstwy aplikacji, która zawiera wsparcie podwarstwą APS (APplication Support), ZDO (ZigBee Device Objects) i zbudowane przez producenta obiekty aplikacji.

Warstwa fizyczna PHY może wykorzystywać jedno z trzech dostępnych pasm o częstotliwościach 2450 MHz (16 kanałów), 915 MHz (10 kanałów) lub 868 $\mathrm{MHz}$ (1 kanał).

Warstwa MAC definiuje dwa typy węzłów: węzły o ograniczonej funkcjonalności RFD (Reduced Function Device) oraz węzły w pełni funkcjonalne FFD (Full Function Device). Pierwsze z nich (RFD) mogą występować jedynie jako węzły końcowe, zarówno w strukturze sieci typu gwiazda, jak i w strukturze typu master-slave.

Porównanie parametrów technologii Bluetooth oraz ZigBee przedstawiono w Tabeli 4. 


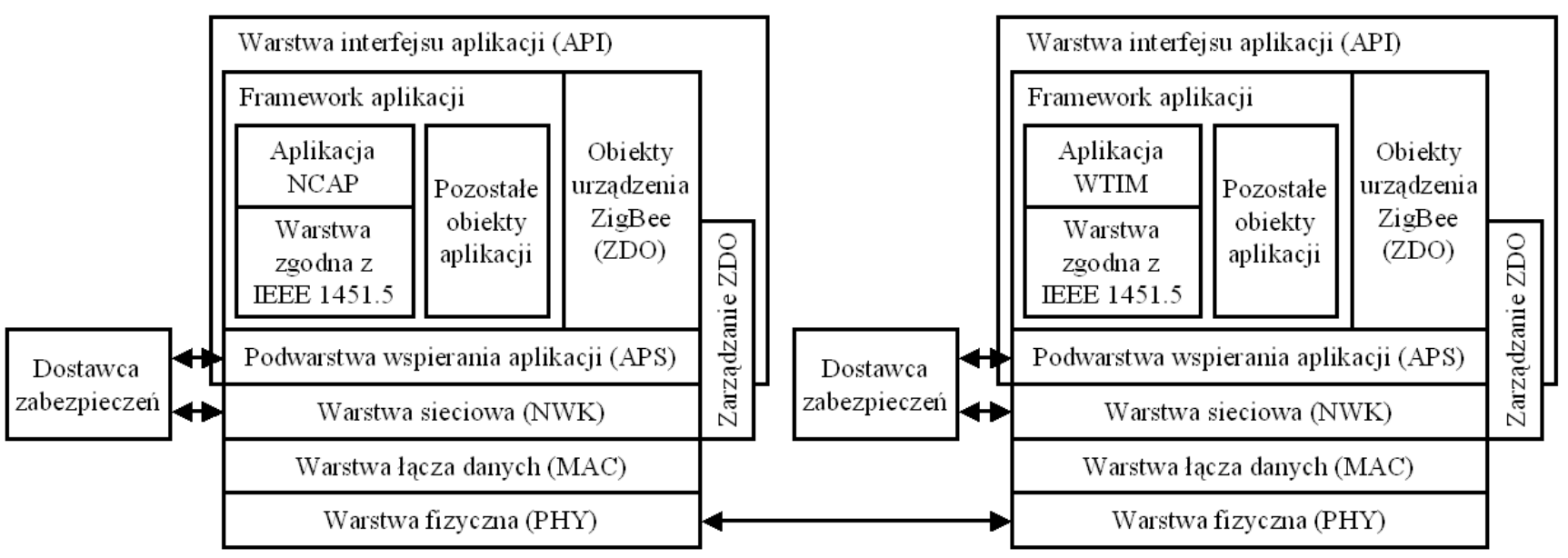

Rys. 5. Schemat architektury systemów standardu ZigBee

Porównanie parametrów sieci urządzeń standardów Bluetooth oraz ZigBee [7, 11].

Tabela 4

\begin{tabular}{|c|c|c|}
\cline { 2 - 3 } \multicolumn{1}{c|}{} & Bluetooth & ZigBee \\
\hline $\begin{array}{c}\text { Standard } \\
\text { protokołu }\end{array}$ & IEEE 802.11 & IEEE.802.15.4 \\
\hline Zastosowanie & Przemysł, medycyna, badania na- \\
ukowe
\end{tabular}

\section{Podsumowanie}

Postęp technologiczny w zakresie sieci bezprzewodowych oraz dostępność układów typu MEMS pozwoliła na skonstruowanie miniaturowych urządzeń pomiarowych. Urządzenia te, połaczone w ramach sieci bezprzewodowej, potrafią nie tylko mierzyć wybrane parametry otoczenia, ale również realizować wyrafinowane procedury oceny stanu układu pomiarowego poprzez analizę i przetwarzanie sygnałów w trybie on-line.

\section{Literatura}

[1] Akyildiz I. F., Su W. J.: Sankarasubramaniam Y., Cayirci E., Wireless sensor networks: a survey. Computer Networks, Vol. 38, 2002.

[2] Bojko T.: Bezprzewodowe systemy pomiarowe dla potrzeb diagnostyki strukturalnej. Pomiary Automatyka Kontrola, Vol. 52, No. 5, 2006.

[3] Eliasz D., Powroźnik P.: Systemy operacyjne w sieciach czujników. Pomiary Automatyka Kontrola, Vol. 53, No. 9, 2007.

[4] Ruiz-Sandoval M., Nagayama T., Spencer B. F. Jr.: Sensor Development Using Berkeley Mote Platform. Journal Earthquake Engineering, Vol. 10, No. 2, 2006.

[5] Spencer B. F. Jr., Ruiz-Sandoval M., Kurata N.: Smart sensing technology: opportunities and challenges. Structural Control Health Monitoring, Vol. 11, 2004.

[6] Zakrzewski J., Czujniki I.: Przetworniki pomiarowe. Wydawnictwo Politechniki Ślaskiej, Gliwice 2006.

[7] BTnodes - A Distributed Environment for Prototyping Ad-hoc Networks, http://www.btnode. ethz. ch/.

[8] Crossbow Technology Inc., http://www. xbow.com/.

[9] Nut/OS - The BTnode operating system core, http://www.ethernut.de/.

[10] TinyOS Community Forum, http://www .tinyos.net/.

[11] ZigBee Alliance, ZigBee Specifications, version 1.0, April 2005. 